\begin{tabular}{c|c} 
Revista Electrónica Teoría de la Educación. \\
Educación y Cultura en la Sociedad de la Información.
\end{tabular}

\title{
EL APRENDIZAJE DIALÓGICO Y SUS APORTACIONES A LA TEORÍA DE LA EDUCACIÓN*.
}

Resumen: Este artículo resalta las contribuciones que el Aprendizaje Dialógico realiza a la Teoría de la Educación avanzando en la perspectiva de la pedagogía crítica y dando orientaciones para una práctica educativa igualitaria y científica. En él se discuten los siete principios del Aprendizaje Dialógico con algunas perspectivas y prácticas educativas reproductoras, mostrando cómo éstos las superan. También se refleja un diálogo abierto con las contribuciones teóricas críticas de la educación en las que se sustenta el Aprendizaje Dialógico incluyendo tanto autores lejanos en el tiempo pero cercanos en planteamientos -Ferrer i Guàrdia, Vygotsky o Paulo Freire- como autores contemporáneos de la pedagogía crítica. Así mismo, se relaciona cada uno de los principios que se presentan con una lectura crítica de la práctica educativa, destacando los efectos de la aplicación del Aprendizaje Dialógico a través del análisis de proyectos educativos innovadores y críticos que, a su vez, muestran buenos resultados educativos.

Palabras clave: Teoría de la educación, pedagogía crítica, transformación social, desigualdades educativas, aprendizaje instrumental.

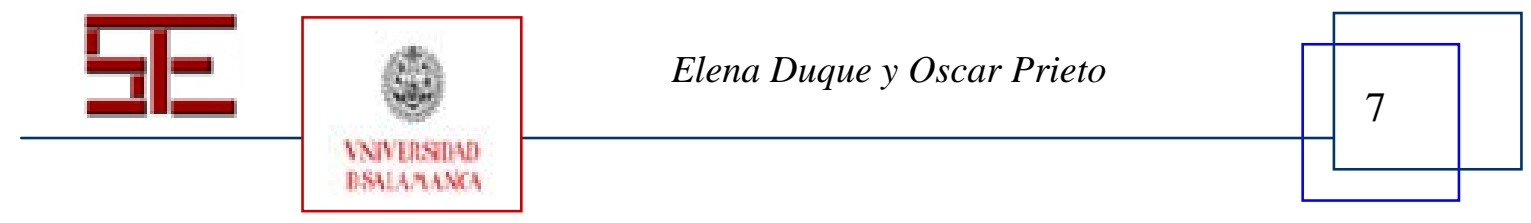




\title{
DIALOGIC LEARNING AND ITS CONTRIBUTIONS TO EDUCATIONAL THEORY
}

\begin{abstract}
This article highlights the contributions of the dialogic learning approach to educational theory, with the aim of providing some orientations in order to promote egalitarian and scientific educational practice. The seven principles of dialogic learning are discussed, along with other reproductionist theories and practices from the educational field, demonstrating how the former both surpass the latter. The article also reflects open dialogue with the critical theories of education which the dialogic learning theory is based on. These basic theories are, on the one hand, by authors who are distant in time but very close in their educational approach, such as Ferrer i Guàrdia, Vygotsky, or Paulo Freire, and, on the other hand, by other contemporary authors in critical pedagogy. Each of the seven principles presented are provided along with a critical examination of a specific educational practice. The consequences of the implementation of dialogic learning are underlined here through an analysis of innovative and critical educational projects which are academically successful.
\end{abstract}

Keywords: Educational theory, Critical Pedagogy, Social transformation, Educational Inequality, instrumental learning.

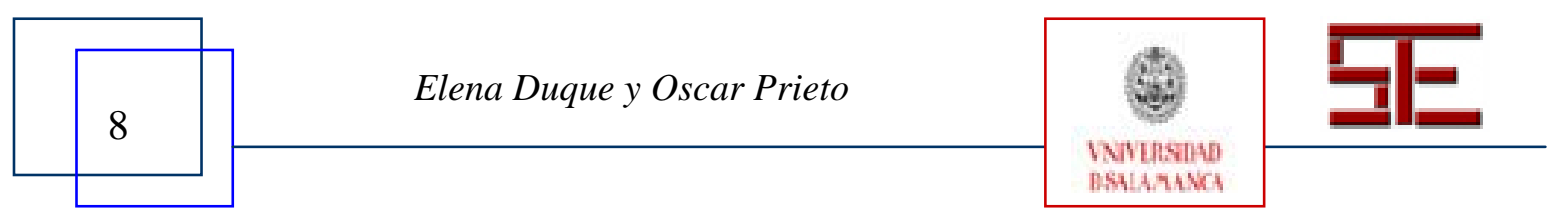




\begin{tabular}{c|c} 
Revista Electrónica Teoría de la Educación. \\
Educación y Cultura en la Sociedad de la Información.
\end{tabular}

\title{
EL APRENDIZAJE DIALÓGICO Y SUS APORTACIONES A LA TEORÍA DE LA EDUCACIÓN
}

\author{
Oscar Prieto \\ Universitat de Girona. \\ oscar.prieto@udg.edu \\ Elena Duque. \\ Universitat de Girona. \\ elena.duque@udg.edu
}

\section{1.- INTRODUCCIÓN}

Desde múltiples posiciones se ha criticado la pedagogía crítica por caer excesivamente en la ideología -y en la no cientificidad - intentando demostrar una realidad que podría quedar lejos de cualquier espacio educativo. Esta teoría educativa del Aprendizaje Dialógico no sólo explora y analiza los espacios educativos en los que se establecen todo tipo de interacciones y prácticas educativas de éxito sino también aquellas que acaecen en otros espacios en los que se desarrolla un currículum y organización escolar reproductor-hegemónica. Desde esta perspectiva se cuenta con un mayor marco analítico que permite analizar nuevas realidades empíricas y tener en cuenta las aportaciones de estas prácticas a la mejora del aprendizaje y a la disminución y/o superación de las desigualdades. Por lo tanto, las diferentes teorías que provienen de la pedagogía crítica, como otro paradigma más dentro de la ciencia, pueden identificar aquellos elementos que reproducen el estatus social actual, como también aquellos que mejoran el aprendizaje para todos y a la vez ofrecen una visión y lectura crítica del mundo. De hecho, algunas teorías clásicas han intentado teorizar sobre el papel de la educación en la sociedad poniendo el énfasis sólo en la reproducción y no en la transformación de ésta (véase Bowles y Gintis, 1976; Jencks, 1972; Baudelot y Establet, 1972; Bourdieu y Passeron, 1970). Posicionándose de este modo, dichas teorías entraron en un círculo de norefutación que no sólo les hacía acientíficas sino que también tuvieron consecuencias no esperadas por sus autores de justificación del orden establecido y de bajas expectativas en que la escuela pudiera hacer algo para la mejora de la sociedad y las oportunidades de los más desfavorecidos. No es propósito ahora de una demostración de mayor cientificidad de unas teorías sobre las otras sino más bien, como sugeriría el mismo Lakatos (1970), de la necesidad de ir avanzando en una más amplia explicación de los fenómenos que nos rodean teniendo en cuenta la ideología predominante y siendo crítica con

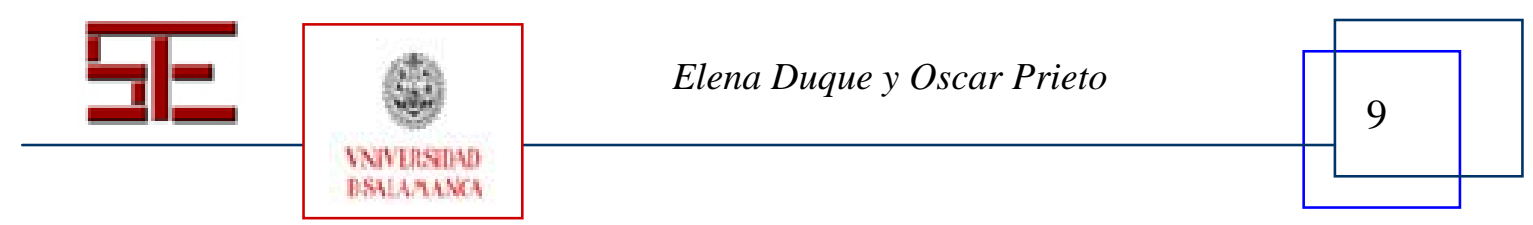


ésta. De esta forma, también se vuelve necesario conocer cuáles son los elementos que pueden favorecer una educación conectada a la transformación de la sociedad. Es difícil que provenga de autoras y autores que defienden la neutralidad valorativa y la ciencia del expertismo en el campo de la educación ${ }^{1}$. Como señala Freire (1999) dicha posición suele introducir en sus teorías un número elevado de argumentos y de juicios de valores que quedan muy lejanos de cualquier práctica educativa. En este sentido, se vuelve necesario que no sólo las teorías críticas de la educación sino cualquiera esté en contacto directo con la realidad educativa y que, de forma crítica y dialogada con la comunidad, se acuerden cuáles son las prácticas educativas que superan las desigualdades. Algo parecido indicaba Jim Cummins al señalar que "la mejor manera de oponerse a las relaciones coercitivas del poder es demostrando los resultados positivos de los programas que implementan una pedagogía transformadora” (Cummins, 2002, 277).

A continuación se presentan los siete principios de la Teoría del Aprendizaje Dialógico definidos por Flecha (1997). En 7 apartados - uno para cada principio -se relaciona cada uno de ellos con una lectura crítica de la práctica educativa tratando de establecer un diálogo teórico con otras contribuciones teóricas, críticas y hegemónicas, de la educación. Uno por uno, se va destacando de cada principio su principal aportación a la teoría de la pedagogía crítica.

\section{2.- DIÁLOGO IGUALITARIO}

Jürgen Habermas (1981) en su Teoría de la Acción Comunicativa refleja cuatro diferentes tipos de acción, la acción teleológica (o estratégica), la acción regulada por normas, la acción dramatúrgica y la acción comunicativa. En el primer tipo, los actores orientan su conducta intentando influenciar en los demás de forma estratégica para así lograr sus objetivos. La segunda comporta que los diferentes actores modelen su conducta en función de unas reglas preestablecidas. Y la tercera aparece cuando uno o varios actores escenifican una determinada imagen a un público concreto controlando el acceso de éste a los verdaderos sentimientos e intenciones latentes en la acción. Estos tres primeros tipos presentados hasta el momento se encontrarían englobados en un marco de racionalidad instrumental en el que se puede alejar a los ciudadanos de la participación democrática ya que suele no dar cabida a pretensiones de validez o a un diálogo igualitario. Un ejemplo donde se puede reflejar estos tres primeros tipos de acción se daría cuando un equipo directivo de un centro escolar promueve la creación de un aula de apoyo (que funciona simultáneamente con las aulas ordinarias) para el alumnado que demuestra más dificultades de aprendizaje. Para ello se intenta convencer a los familiares para que sus hijos e hijas acudan a dicha aula mientras que el grupo-clase sigue trabajando el currículum ordinario (acción estratégica). De este modo, se decidirá a partir de unos parámetros normativos qué alumnos son los que deben asistir al aula de apoyo (acción regulada por normas) que es presentada con gran entusiasmo por el equipo directivo y la maestra de educación especial (acción dramatúrgica).

El cuarto tipo de acción conllevaría un cambio de paradigma en lo anteriormente anunciado. Según Habermas, "sólo el concepto de acción comunicativa presupone el lengua-

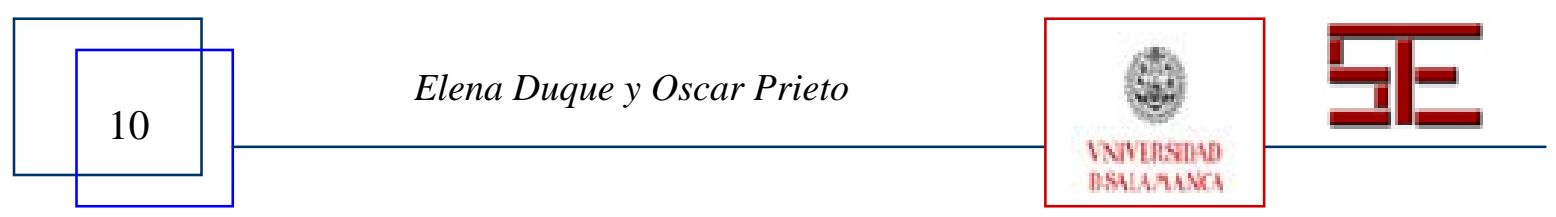




\begin{tabular}{c|c} 
Revista Electrónica Teoría de la Educación. \\
Educación y Cultura en la Sociedad de la Información.
\end{tabular}

je como medio de entendimiento para negociar definiciones de la situación que puedan ser compartidas por todos” $(1981,137-138)$. Desde la acción comunicativa se da pie al diálogo entre los diferentes agentes en los que prima el entendimiento y la exposición de argumentos basados en pretensiones de validez ${ }^{2}$ por encima de cualquier orientación de la acción que intente influenciar intencionalmente en la opinión de los demás. Un ejemplo de ello se refleja en la misma situación anterior orientada de forma comunicativa. En una de las asambleas donde suelen asistir familiares, profesorado y representantes de la comunidad se propone la posibilidad de crear un aula de apoyo. Una madre destaca que en una escuela que conoce el apoyo al alumnado se lleva a cabo de forma diferente. En vez de crear un aula adicional se considera más conveniente que el educador o educadora entre en el aula con todo el grupo-clase coordinándose con la maestra. Y llevando a cabo una organización que atienda a la diversidad mediante la formación de grupos interactivos heterogéneos ${ }^{3}$. El profesorado desconocía o simplemente no había tenido en cuenta esta posibilidad y solicitó recibir formación específica sobre dichas prácticas. Finalmente, se escogió la opción explicada anteriormente porque no conllevaba la estigmatización de los alumnos y se observaban mejoras significativas en el alumnado.

En 1970, Paulo Freire ya identificaba las diferencias entre acción instrumental y acción comunicativa en educación. "De ahí que [el diálogo] no pueda ser mañoso instrumento del cual eche mano un sujeto para conquistar a otro. La conquista implícita en el diálogo es la del mundo por los sujetos dialógicos, no la del uno por el otro” $(1970,106)$.

Los conceptos de acción instrumental y de acción comunicativa o dialógica son útiles para identificar dos tipos de relaciones que tienen un papel fundamental en educación, las de poder y las dialógicas. Ambas están formadas por el conjunto de interacciones que existen entre los sujetos a través de medios verbales o no verbales (Searle y Soler, 2004). Las relaciones sociales en cualquier ámbito pueden ir orientadas o bien hacia el diálogo y la participación de los diferentes agentes sociales o, por el contrario, hacia la imposición y/o la inhibición de éstos. Las relaciones de poder no sólo son propias de las dictaduras sino también de las democracias representativas donde suelen aparecer de forma simbólica. Por ejemplo, como señala Joe L. Kincheloe (2008) la burocratización y/o la tecnocracia convierten la adquisición del conocimiento en un proceso acomodaticio en el que no se invita a reflexionar sobre el por qué aprender unos conocimientos y no otros, así como a identificar las pretensiones de poder que éstos conllevan. En un contexto representativo también las familias, el alumnado y la comunidad suelen quedar fuera de juego y es difícil dar sentido a las materias, contextualizar los contenidos y tomar las decisiones que se establecen en un entorno educativo a partir de sus intereses y motivaciones. También suelen acaecer tensiones de culpabilidad mutua entre maestros y/o profesores y familias. En este sentido, algunos proyectos educativos, como Comunidades de Aprendizaje ${ }^{4}$, han dado la vuelta a esta situación estableciendo una nueva organización que tiene como meta favorecer el diálogo igualitario entre los diferentes actores $^{5}$.

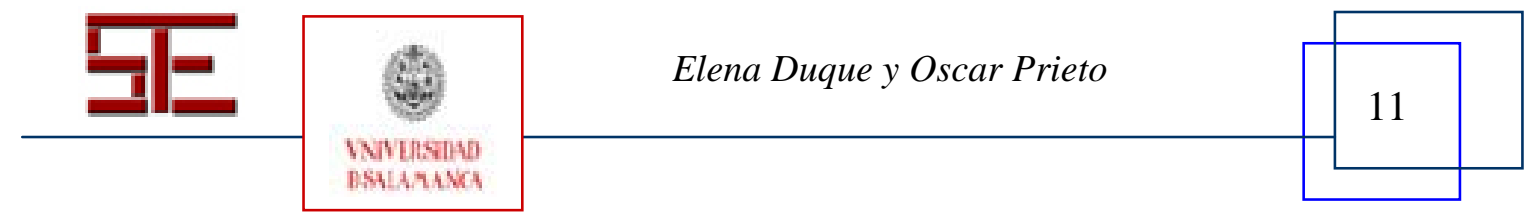




\section{3.- INTELIGENCIA CULTURAL}

Tradicionalmente, en el mundo de la educación el concepto hegemónico de inteligencia que ha imperado ha sido el de la inteligencia académica. Más específicamente, este tipo de habilidad se ha medido tradicionalmente a través del coeficiente intelectual (CI o IQ en inglés). Los tests psicológicos cuantitativos han etiquetado a muchos alumnos y alumnas como deficitarios o no válidos condicionando su vida escolar, laboral y social. En 1994, Richard J. Herrnstein y Charles Murray argumentaron que el éxito de las personas que se encontraban en lo más alto de la jerarquía social era debido a su inteligencia -calculada a través del CI - y no a su origen socioeconómico o étnico. Por lo contrario, aquellas personas que se quedan atrás en un sistema meritocrático lo hacen por su bajo coeficiente intelectual y no por su condición social. Esta obra titulada Bell Curve generó muchas críticas entre científicos sociales pero también alabanzas entre otros como el economista Milton Friedman.

Dicha visión reduccionista sobre la inteligencia no tiene en cuenta que el alumnado no haya alcanzado las puntuaciones necesarias porque el test no refleja un lenguaje familiar o por otro tipo de motivos. Basil Bernstein (1971) en su teoría de los códigos lingüísticos ya indicaba que la lengua escolar se emite en códigos lingüísticos elaborados mientras que una buena parte de los estudiantes no poseen dichas habilidades académicas. De esta forma, los tests suelen evaluar si los alumnos las dominan y no si poseen mayor o menor coeficiente intelectual.

Además de la inteligencia académica existen otro tipo de inteligencias que han quedado tradicionalmente al margen del sistema educativo y que éste debe tener en cuenta si su pretensión es la equidad. Por ejemplo, autores como Howard Gardner (1983) o Sternberg y Wagner (1986) han destacado que cada individuo presenta varios niveles de diferentes inteligencias y que hay que tener todas ellas en cuenta. Concretamente, los segundos diferenciaron entre el concepto de inteligencia académica -aquella que se desarrolla en espacios académicos - y el concepto de inteligencia práctica -desarrollada en espacios de vida cotidiana. Algunas personas pueden tener una baja inteligencia académica pero una elevada inteligencia práctica debido a su experiencia cotidiana y a la inversa. Por ejemplo, un trabajador de un taller mecánico puede asesorar a un ingeniero mecánico en la elaboración de una nueva máquina debido a su experiencia previa.

Tradicionalmente, la educación ha tendido a obviar las experiencias y los conocimientos de los estudiantes que son básicos para la motivación y aprendizaje. Kincheloe, Steinberg y Villaverde (1999) destacan la necesidad de que el proceso de enseñanza aprendizaje tenga en cuenta la vida cotidiana del estudiante. Los procesos educativos que sólo tienen en cuenta la inteligencia académica y suelen dejar de lado la experiencia

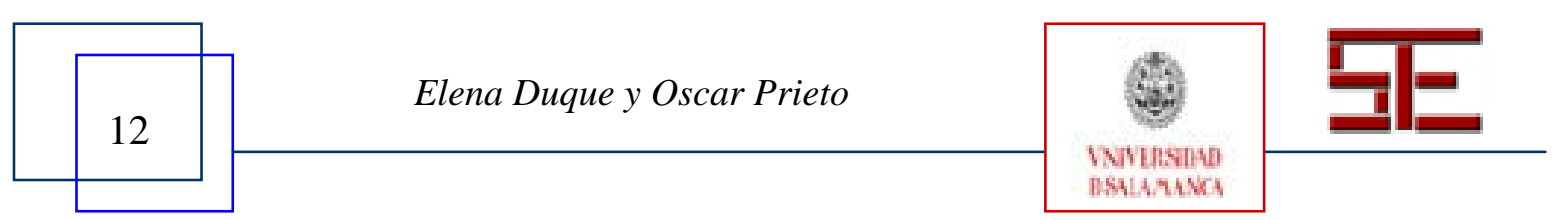




\begin{tabular}{c|c} 
Revista Electrónica Teoría de la Educación. \\
Educación y Cultura en la Sociedad de la Información.
\end{tabular}

cotidiana del alumnado caen, según el autor y la autora, en una ingeniería educativa de la racionalidad técnica que pone el énfasis en los resultados sin tener en cuenta el entorno, los procesos de aprendizaje y las motivaciones del alumnado. En este tipo de clase, los alumnos de entornos desaventajados tienden a sentirse incompetentes y se les etiqueta como alumnos de bajas habilidades cognitivas. Algunas soluciones hegemónicas a este tipo de casos suelen reflejarse en la adaptación del currículum en relación a sus “capacidades" produciendo estigma y bajas expectativas en vez de lo contrario, la promoción de una acción afirmativa que les ayude a alcanzar unas habilidades académicas similares a las de sus compañeros y compañeras.

El Aprendizaje Dialógico parte de la concepción de Inteligencia cultural (Flecha, 1997) que engloba no sólo la inteligencia académica y la inteligencia práctica anteriormente citadas. También tiene en cuenta un tercer elemento, la inteligencia comunicativa. Todo ser humano posee capacidad de lenguaje y comunicación (Chomsky, 1988) y aunque no disponga de inteligencia académica o práctica puede entrar en interacción con otros preguntando o aportando conocimiento. Por ejemplo, aunque un alumno no tenga el conocimiento teórico y práctico sobre como sumar o restar puede ser ayudado por otro alumno que los posee a través de la interacción y el diálogo. Los grupos interactivos heterogéneos pueden garantizar estos procesos de enseñanza-aprendizaje entre iguales teniendo en cuenta las diferentes tipologías de inteligencia.

\section{4. -TRANSFORMACIÓN}

El compromiso con la transformación de la sociedad es uno de los elementos básicos del Aprendizaje Dialógico. Este fundamento recoge dos puntos clave: a) el del rol y el compromiso del maestro o la profesora ${ }^{6} \mathrm{y}$ b) el de los centros educativos por aplicar una pedagogía transformadora que minimice o supere las desigualdades sociales. La conjunción e interacción de ambos elementos ayuda a disminuir la distancia que existe hegemónicamente entre escuela, familia y comunidad así como el aprendizaje del alumnado.

a) El rol de la maestra es importante en el seno de la comunidad educativa como el de cualquier otro actor. La transmisión del conocimiento en la actual sociedad de la información ya no es exclusiva de esta figura como lo fue en la escuela tradicional sino más bien su papel actual debería consistir no sólo en la mediación del conocimiento sino también en su cuestionamiento crítico. Actualmente, el conocimiento se transmite por diferentes canales, como por ejemplo Internet, y por múltiples fuentes a los que la escuela ha de dar una respuesta de forma crítica. Promover el diálogo crítico o no promoverlo conlleva consecuencias importantes en la selección y el proceso de la información relevante. Por ejemplo, no es lo mismo leer en una clase de una escuela de un entorno obrero un best seller plagado de errores históricos a una novela clásica sobre los mis-

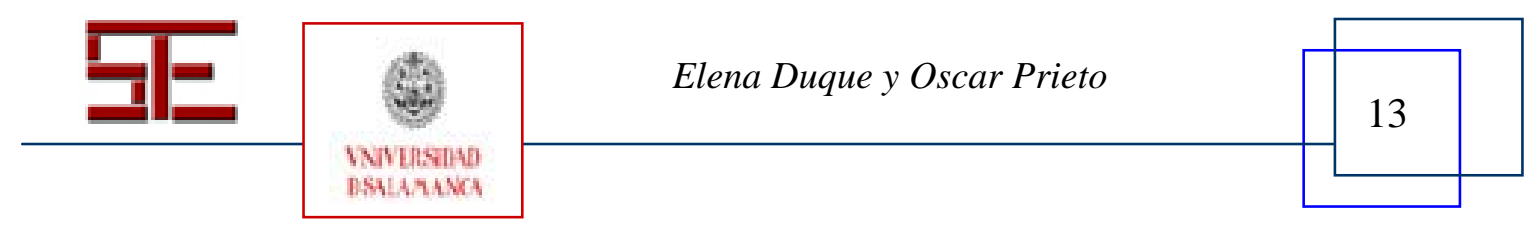


TESI, 10(3), 2009, 7-30

mos hechos, tampoco lo es tratar en clase una noticia o artículo de opinión sobre la guerra de Iraq sin preguntarse de dónde proviene, de si existen otras visiones y si éstas respetan los derechos humanos.

Para el docente, tener presentes aquellas prácticas educativas dentro y fuera del aula que reproducen las desigualdades y aquellas que las disminuyen o las reducen puede marcar significativamente su ejercicio. Como se ha demostrado en algunas investigaciones científicas, como el proyecto europeo INCLUD-ED ${ }^{7}$, la organización del aula en grupos interactivos heterogéneos, además de promover la solidaridad, favorece el aprendizaje instrumental de todos los alumnos, tanto el de aquellos que tienen más dificultades como el de los más aventajados. Esta puesta en práctica de este tipo de metodología se suele complementar con una visión de altas expectativas del profesor o maestra sobre sus alumnos superando una percepción paternalista de sus alumnos y sus familias a la vez que se les ofrece confianza. Es decir, transformando el contexto educativo en un espacio de altas expectativas y no adaptándolo al entorno donde se situaría el alumno. Este espíritu también se encontraba en la Escuela Moderna de Francesc Ferrer i Guàrdia que promovía una enseñanza basada en la ayuda mutua, en la solidaridad entre el alumnado y la crítica de las injusticias mediante el estudio de los mecanismos y condiciones que las hacían posibles (Solà, 2008).

El papel del maestro y el profesorado ha sido tratado por la pedagogía crítica recogiendo algunas aportaciones teóricas relevantes de Antonio Gramsci (1935) como los conceptos de Intelectual radical orgánico y de Intelectual conservador orgánico que han sido aplicados al ámbito de la educación. Así lo recogen algunos autores como Paulo Freire (1999) que atribuye el rol de intelectuales a cualquier persona, hombre o mujer, al ser capaces de interpretar los significados de su mundo de la vida y con los que se puede establecer un diálogo educativo que transforme su entorno más inmediato. Específicamente Henry Giroux destaca que los maestros pueden convertirse en intelectuales radicales orgánicos acercando el mundo académico al de la vida cotidiana y promoviendo la adquisición de habilidades políticas y morales con el objetivo de fundar nuevas instituciones populares de educación. En esta línea, los maestros pueden ser educados como "intelectuales transformadores capaces de afirmar y practicar la palabra de la libertad y la democracia” (Giroux, 1988, 159-160). La aportación de Giroux es muy valiosa y el papel del maestro que propone podría complementarse con un maestro que parte del diálogo, de los conocimientos previos de sus alumnos y que es capaz de que sus alumnos adquieran un lenguaje académico para expresar aquello que ya conocen desde su experiencia cotidiana. También lo es la de Gordon Wells (2001) que destaca que algunos maestros incluyen a sus estudiantes y colegas como colaboradores potenciando una interpretación nueva, más igualitaria y más recíproca que la de un modelo tradicionalvertical.

La acomodación de una parte considerable del profesorado, la burocratización del sistema escolar y el peso de algunas creencias conservadoras y/o corporativas legitiman el status quo actual y obstaculizan la transformación educativa y social. Pero para que se

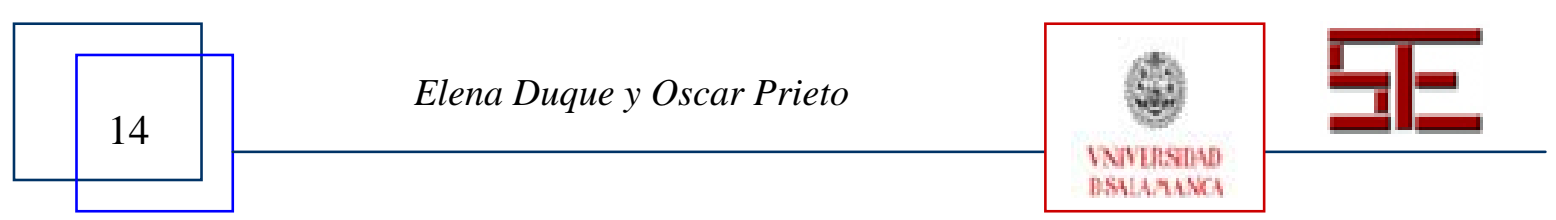




\begin{tabular}{c|c} 
Revista Electrónica Teoría de la Educación. \\
Educación y Cultura en la Sociedad de la Información.
\end{tabular}

de dichos cambios educativos no sólo basta con que existan maestras y maestros comprometidos con la transformación. También son necesarios algunos compromisos institucionales.

b) El compromiso de las instituciones educativas en aplicar una pedagogía transformadora que minimice o supere las desigualdades sociales también es clave para poder llevar a cabo en las mejores condiciones el Aprendizaje Dialógico. Muchos profesores y profesoras que tienen la ilusión y el compromiso de trabajar por una mejor educación de su alumnado se topan, en ocasiones, con la desmotivación de sus compañeros y un engranaje burocrático que les impide llevar a cabo con éxito sus propósitos. Algunas escuelas se han comprometido socialmente con su entorno a través de un lenguaje de la posibilidad creando un espacio educativo global que no sólo incluye la formación del alumnado sino también de los familiares y de otros miembros de la comunidad.

Algunas investigaciones realizadas desde la óptica de la economía de la educación han indicado cuáles son los elementos que suelen afectar de forma más directa al rendimiento académico del alumnado. Éstos son la calidad del profesorado (Hanushek, 2002) y el capital humano y social de su entorno (Carnoy, Gove y Marshall, 2007). Algunos proyectos educativos promueven el desarrollo de ambos elementos especialmente del segundo, promoviendo la participación y la formación de los familiares y de la comunidad para poder ayudar a sus hijos e hijas/ciudadanos y ciudadanas en sus deberes tanto en casa como en la misma escuela ya que ésta se encuentra abierta a la comunidad. Por ejemplo, los centros de Comunidades de Aprendizaje en España o del Harlem Children's Zone $e^{8}$ en Estados Unidos se encuentran abiertos a los familiares y garantizan su formación. De forma crítica, se vuelve necesario impulsar una educación no sólo para que los alumnos salgan de la situación de pobreza en la que viven y puedan acceder a la universidad el día de mañana sino también para que exista un compromiso social de éstos y de la comunidad educativa con la transformación del entorno. Como afirma Amartya Sen, se vuelve necesario apostar por aumentar los niveles de educación de la población no exclusivamente en términos de producción económica y de competencia (Sen, 1997) sino también en otro tipo de valores que promuevan la solidaridad y la visión crítica del mundo.

\section{5.- DIMENSIÓN INSTRUMENTAL}

El aprendizaje instrumental ha sido tradicionalmente uno de los elementos clave de la educación. Las teorías educativas han conceptualizado, analizado y propuesto cómo es posible enseñar y adquirir los aprendizajes instrumentales. También han discutido la relación entre aprendizaje instrumental y diálogo, generalmente colocándolos como opuestos, a más diálogo menos aprendizaje instrumental. Así mismo la adquisición de aprendizajes instrumentales ha sido tema de debate en relación a los grupos más desfa-

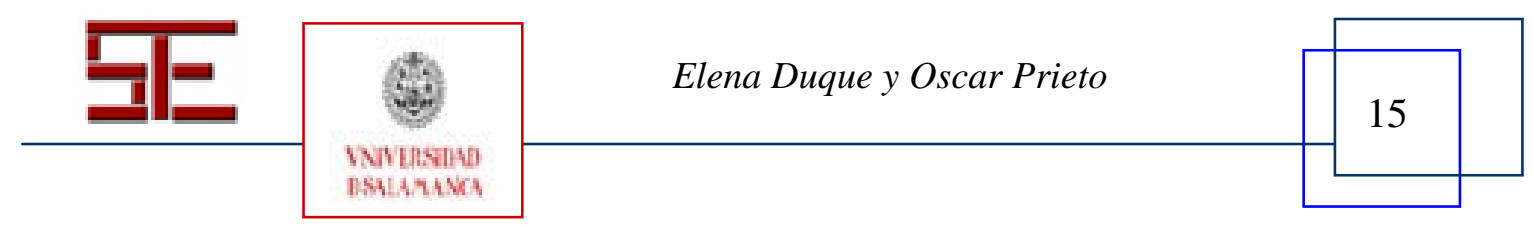


vorecidos, llevando a cuestionar si ciertos colectivos realmente requieren un alto nivel de dicho aprendizaje. Este último planteamiento se refleja actualmente en varios centros educativos cuando se reducen los objetivos de aprendizaje y la calidad del mismo para colectivos en situación social más desfavorecida. Por otro lado los bajos resultados en evaluaciones internacionales sobre, por ejemplo, el nivel de lectura en España, resultan alarmantes. De esta forma el aprendizaje instrumental sigue siendo un elemento clave y una preocupación social y educativa. En este apartado se resaltan tres aportaciones principales del Aprendizaje Dialógico desde la dimensión instrumental referidas al deber de las escuelas de asegurar un aprendizaje instrumental de calidad, la importancia de esta dimensión instrumental en relación a los grupos más desfavorecidos y las teorías que sustentan un aprendizaje instrumental de calidad para todas las personas.

\section{1.- El aprendizaje instrumental: prioridad de la escuela}

Si bien la escuela se creó con el objetivo de enseñar una serie de aprendizajes, actualmente parece que esto se olvida en ocasiones. Algunas y algunos profesionales de la educación, mayoritariamente en contextos desfavorecidos, se centran en conseguir "que no haya conflicto” y que se aprendan las “cuatro reglas básicas”. A veces las horas lectivas se ocupan con "aprendizajes para la convivencia” restando horas a los aprendizajes instrumentales. Mientras, en otros centros educativos de contextos socialmente más privilegiados, el mismo objetivo de "que no haya conflictos" no va reñido con la calidad del aprendizaje. La concepción objetivista del aprendizaje, la más tradicional, partía de que el objetivo de la escuela es enseñar, es el aprendizaje. Su concepción de este aprendizaje se reducía a la transmisión de saberes de una persona experta (profesorado) a unas personas receptoras inexpertas (alumnado) consideradas homogéneas, favoreciendo que este aprendizaje sólo fuera adquirido por algunos colectivos. Esta perspectiva educativa es la que Freire denomina educación bancaria. "En la visión "bancaria" de la educación, el "saber", el conocimiento, es una donación de aquellos que se juzgan sabios a los que juzgan ignorantes. Donación que se basa en una de las manifestaciones instrumentales de la ideología de la opresión: la absolutización de la ignorancia, que constituye lo que llamamos alienación de la ignorancia, según la cual ésta se encuentra siempre en el otro" (Freire, 1970, 79).

Desde una concepción constructivista la prioridad del aprendizaje instrumental se relativiza. El subjetivismo en el que se enmarca propicia que los objetivos de aprendizaje no sean igual de prioritarios, ni de la misma calidad, dependiendo de la individualidad de cada estudiante. La teoría de la asimilación de Ausubel (1962) y su propuesta de aprendizaje significativo basado en conocimientos previos promueve este relativismo. Para enseñar se han de tener en cuenta los conocimientos previos de cada alumno, y enseñar a partir de ahí mediante objetivos individualizados que se alejan de un objetivo igualitario de que todo el alumnado acceda a un aprendizaje instrumental de calidad. De esta forma, a quien ya sabe más se le enseña más, a quien sabe menos, se le enseña menos, siguiendo el efecto Mateo (Merton, 1977). El aprendizaje es también un objetivo de la escuela. Pero si esta escuela está en un contexto socioeconómico desfavorecido, y de

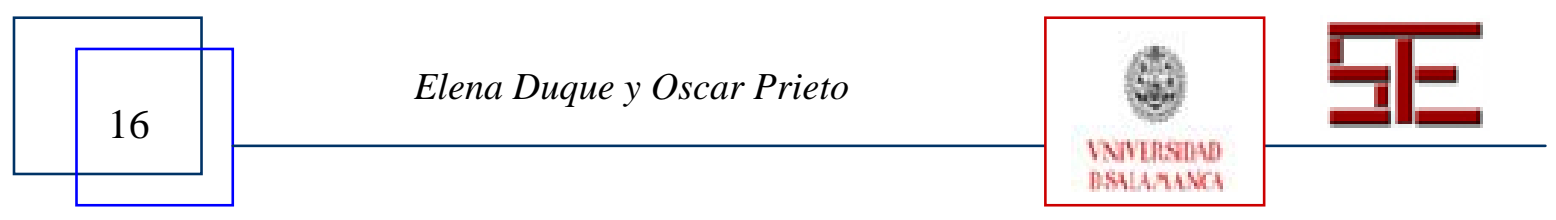




\begin{tabular}{c|c} 
Revista Electrónica Teoría de la Educación. \\
Educación y Cultura en la Sociedad de la Información.
\end{tabular}

forma generalizada se considera que los conocimientos previos de ese alumnado no tienen un alto nivel, la enseñanza no va dirigida a que este alto nivel se alcance, sino a que aprendan "algo más” teniendo en cuenta su punto de partida.

Desde la concepción dialógica y desde la pedagogía crítica, la escuela tiene el papel esencial de asegurar un aprendizaje instrumental de calidad para todo el alumnado. Así lo plantea Ladson-Billings en su teoría sobre la pedagogía culturalmente relevante donde el primer criterio es el éxito académico de las y los estudiantes, "El foco de la clase debe ser instruccional. Aunque un aula es un lugar complejo y dinámico, la primera empresa debe ser enseñar. En aulas culturalmente relevantes, la enseñanza es lo principal” (Ladson-Billings, 1994, 124). Es en este enfoque donde se enmarca el Aprendizaje Dialógico tomando como base a otros autores como Freire (1997) que plantea la existencia de una curiosidad epistemológica que todas las personas tenemos, y que puede verse frustrada por la reducción de objetivos en nombre de una adaptación al contexto y a las necesidades individuales. El Aprendizaje Dialógico promueve por tanto que el aprendizaje instrumental de calidad sea una prioridad de las escuelas, sin que ello esté reñido -como discutiremos más adelante-sino unido con un planteamiento de diálogo y solidaridad.

\section{2.- Aprendizaje instrumental de calidad para personas desfavorecidas}

Las personas más desfavorecidas han sufrido desde planteamientos objetivistas y constructivistas la exclusión de los procesos de aprendizaje instrumental. Una enseñanza tradicional que trata de forma homogénea a todo el alumnado se centra en la transmisión vertical de saberes y no permite la participación activa ni recoge las contribuciones de la propia comunidad, margina a la población cuyo contexto social no conecta con el de la escuela.

Por otra parte, desde la perspectiva constructivista, la adaptación curricular según las necesidades individuales y el contexto se deriva muchas veces en reducir contenidos a los grupos más desfavorecidos. Al alumnado en desventaja, argumentando que se ha de partir de sus conocimientos previos, se le enseñan menos contenidos, y se reduce el aprendizaje instrumental. "La motivación académica de los negros y de otros alumnos marginados culturalmente puede ser aumentada: [...] d) concentrándose en el dominio de destrezas intelectuales básicas antes de introducirlos a materias más complejas, en lugar de recurrir a la práctica omnipresente de la "promoción social" (la cual produce estudiantes graduados preuniversitarios funcionalmente ignorantes)" (Ausubel, Novak y Hanesian, 1978, 400). Con estos planteamientos el autor propone que a grupos más desfavorecidos no se les den contenidos curriculares de calidad, con un aprendizaje básico es suficiente. Como en algunas escuelas de nuestros días se comenta "con que sepan leer y escribir y hacer algunas cuentas, ya basta”. De esta forma se reducen objetivos para aquellas personas más desfavorecidas mientras que se mantienen y promueven

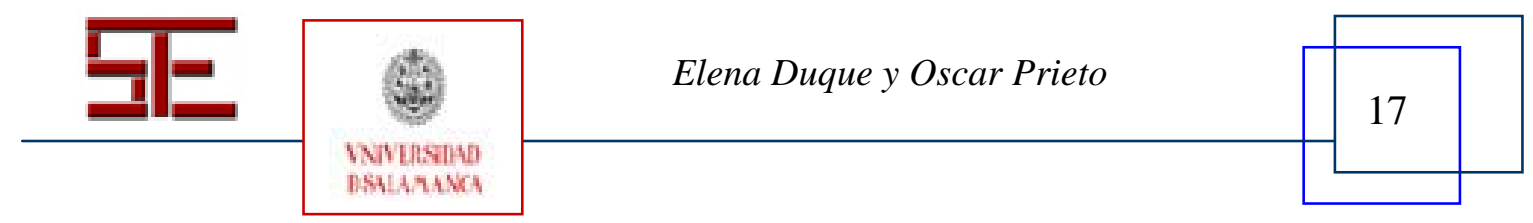


objetivos de calidad educativa para los grupos más privilegiados o no marginados. Según el planteamiento de Ausubel también, uno de los elementos clave del aprendizaje es la motivación del alumnado. El autor afirma explícitamente respecto a los colectivos más marginados que esta motivación no existe: "Debe concederse desde el principio que el niño culturalmente marginado manifiesta de manera característica poca motivación intrínseca por aprender” (Ausubel, Novak y Hanesian, 1978, 427). Así toda falta de motivación e interés por aprender se atribuye al propio alumnado obviando los efectos que la exclusión o marginación que sufren está teniendo en su aprendizaje.

Sin embargo, otros autores, desde la pedagogía crítica, no sólo desmantelan esta teoría sino que abogan por una educación de mayor calidad y por más aprendizaje instrumental para los colectivos más desfavorecidos. Cole y Scribner (1977) afirman que no existe relación entre clase baja y motivación y/o inteligencia. Apple (1995) plantea que si a los grupos más desfavorecidos sólo se les dan conocimientos prácticos se les deja en desventaja, y que la escuela democrática tiene que dar acceso a todos y todas las estudiantes al conocimiento y permitir así romper barreras socioeconómicas.

La pedagogía crítica siempre ha promovido la educación de calidad para las personas más desfavorecidas. Ferrer i Guàrdia desde la Escuela Moderna defendía, promovía y llevaba a cabo esta educación de calidad.

“ La verdad es de todos y socialmente se debe a todo el mundo. Ponerle precio, reservarla como monopolio de los poderosos, dejar en sistemática ignorancia a los humildes y, lo que es peor, darles una verdad dogmática y oficial en contradicción con la ciencia para que acepten sin protesta su ínfimo y deplorable estado, bajo un régimen político democrático es una indignidad intolerable, $\mathrm{y}$, por mi parte, juzgo que la más eficaz protesta y la más positiva acción revolucionaria consiste en dar a los oprimidos, a los desheredados y a cuantos sientan impulsos justicieros esa verdad que se les estafa, determinante de las energías suficientes para la gran obra de la regeneración de la sociedad”. (Ferrer i Guàrdia, 1908).

El Aprendizaje Dialógico desmonta también este supuesto desinterés de las personas más desfavorecidas a través de investigaciones científicas donde estos colectivos participan. La investigación Brudila Calli ${ }^{9}$, recoge las voces de las niñas, adolescentes y mujeres gitanas. En ella se analiza por qué puede haber un rechazo a la institución escolar en algunos casos, un rechazo que no es producto de la desmotivación por aprender sino fruto en varias ocasiones de que la escuela no esté realizando su función principal de enseñar. La investigación de Sordé (2006) también profundiza en estos aspectos, analizando las movilizaciones de las mujeres gitanas en su reivindicación de una educación de calidad.

En la práctica el Aprendizaje Dialógico supera los dobles discursos de las y los profe-

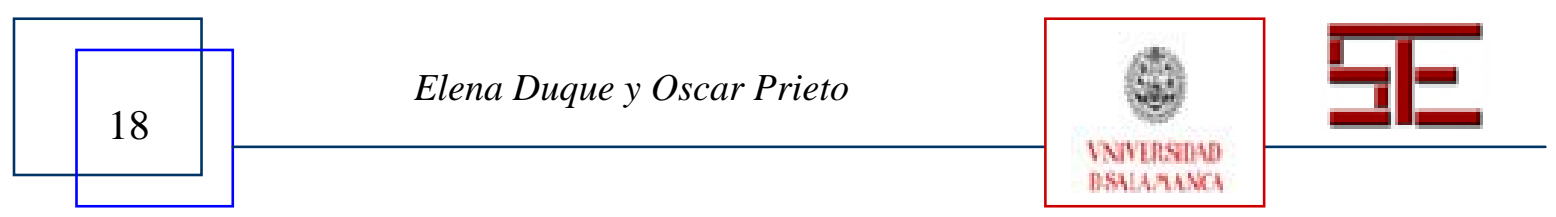




\begin{tabular}{c|c} 
Revista Electrónica Teoría de la Educación. \\
Educación y Cultura en la Sociedad de la Información.
\end{tabular}

sionales de la educación que promueven la reducción de objetivos para colectivos más desfavorecidos mientras enfatizan la dimensión instrumental para sus propios hijos e hijas. Consecuentemente desmonta las medidas de atención a la diversidad, basadas en adaptaciones curriculares que eliminan contenidos. "Lo que la realidad nos muestra es que precisamente aquello que más necesitan las niñas y los niños de entornos desfavorecidos para superar la exclusión social o minimizar el riesgo de estar excluidos es una buena preparación académica que enfatice la dimensión instrumental del aprendizaje” (Aubert, Flecha, García, Flecha y Racionero, 2008, 203).

5.3.- Aprendizaje instrumental para todas y todos a través de las interacciones y mediante el diálogo

Como bien es sabido, la concepción objetivista, la enseñanza tradicional, basa el aprendizaje en la memorización y asimilación de saberes transmitidos desde una perspectiva conductista que promociona la recompensa y el castigo. Un planteamiento subjetivista, constructivista, como ya se ha referido anteriormente, construye los aprendizajes individualmente partiendo de los conocimientos previos.

Desde la perspectiva dialógica y comunicativa son las interacciones en grupos heterogéneos las que permiten alcanzar los máximos aprendizajes instrumentales. Vygostky (1995, 1996) plantea que todo conocimiento individual ha sido previamente social. Es decir, que los conocimientos que tiene una persona son fruto de las interacciones que ha establecido. Por tanto su aumento de aprendizaje también dependerá de las interacciones que establezca. "lo que un niño es capaz de hacer hoy con ayuda de alguien, mañana podrá hacerlo por sí solo" (Vygotsky, 1920, 134). Vygotsky teoriza sobre la Zona de Desarrollo Próximo (ZDP) que se encuentra entre el nivel real de desarrollo (lo que el alumnado puede hacer por sí sólo) y el nivel de desarrollo potencial (lo que podría llegar a hacer). La interpretación constructivista de esta teoría ha centrado el aprendizaje en adaptar los contenidos al nivel real de desarrollo avanzando en la ZDP. En el planteamiento de Vygotsky, el objetivo es centrar el aprendizaje en alcanzar el nivel de desarrollo potencial. Así, mediante las interacciones, la ZDP se recorre. También otros autores plantean las interacciones como potenciadoras del aprendizaje (Habermas, 2001; Rogoff, 1993; Mead, 1934).

El Aprendizaje Dialógico se basa en las investigaciones científicas de mayor relevancia internacional, entre ellas el antes mencionado Proyecto Integrado INCLUD-ED. En los primeros resultados de esta investigación se evidencia cómo el trabajo en grupos heterogéneos en las aulas promueve la mejora del aprendizaje. También realiza importantes aportaciones sobre cómo la participación de la comunidad educativa en la escuela promueve el aumento y diversidad de las interacciones incidiendo en un mejor desarrollo del aprendizaje. Dentro de la promoción de más y más diversas interacciones, el Aprendizaje Dialógico realiza una aportación más diferenciando entre interacciones dialógicas

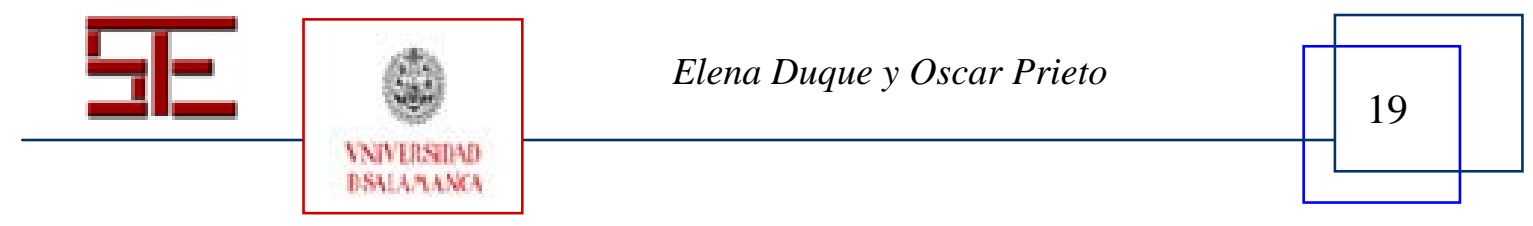


e interacciones de poder (Searle y Soler, 2004). El Aprendizaje Dialógico muestra cómo el aprendizaje instrumental aumenta cuando se establecen interacciones dialógicas, es con estas interacciones que se aprende más. “Así, el objetivo en los centros educativos debería ser buscar las formas necesarias para ir progresivamente transformando las interacciones de poder en interacciones dialógicas” (Aubert, Flecha, García, Flecha y Racionero, 2008, 130).

\section{6.- CREACIÓN DE SENTIDO}

Max Weber rescata el concepto de "desencantamiento del mundo" de Friedrich Schiller para reflejar cómo los procesos de racionalización técnica y con arreglo a fines de las sociedades occidentales quedan desprovistos de sentido para los ciudadanos. Según Weber, el sistema económico y el público-estatal someten a sus imperativos de competitividad y legalidad a los sujetos promoviendo el individualismo y la despersonalización de las relaciones humanas (Weber, 1922). A través de esta objetivación de las relaciones sociales que se dan en el marco de las instituciones públicas y, también de las escuelas, la burocratización se apodera de la espontaneidad de la opinión y de la voluntad colectiva, facilita la desconexión de las decisiones políticas y la pérdida de legitimidad. Para Habermas (1981) es necesario superar dicha "colonización sistémica del mundo de la vida” para devolver el sentido de las instituciones públicas (y educativas) al mundo de los ciudadanos dotándolas de sentido y de relaciones más humanas a través de la acción comunicativa.

\section{1.- Sobre la crisis o pérdida de sentido en la educación}

La crisis o pérdida de sentido en la educación aparece bajo diferentes formas. Para algunas personas la ruptura con valores tradicionales, como la figura de autoridad del profesorado, suponen una pérdida de sentido. Sin embargo, que en las escuelas del siglo XXI un profesorado autoritario no tenga cabida no es una señal de crisis sino de democratización educativa. El abanico de posibilidades, los riesgos que conlleva cada decisión (educativa y no educativa) que se toma generan una situación de incertidumbre que a veces se concreta en crisis de sentido. No obstante, crear nuevas formas de relación entre los miembros de la comunidad educativa, más democráticas, crea un nuevo sentido a la educación.

Por otra parte, se da una crisis de sentido en la educación cuando lo que se enseña en la escuela no tiene ninguna relación con lo que ocurre fuera de ella. Hay crisis de sentido para el alumnado que va a la escuela y no aprende, y ve cómo lo que se le enseña es "para pasar el rato" o no tiene ninguna relación con su vida personal, familiar, social, ni con lo que está sucediendo en el mundo. El encapsulamiento del conocimiento escolar como lo denomina Engeström (1996) es esta separación entre vida cotidiana y centro educativo. Este encapsulamiento deja a las familias fuera del currículo y la educación y

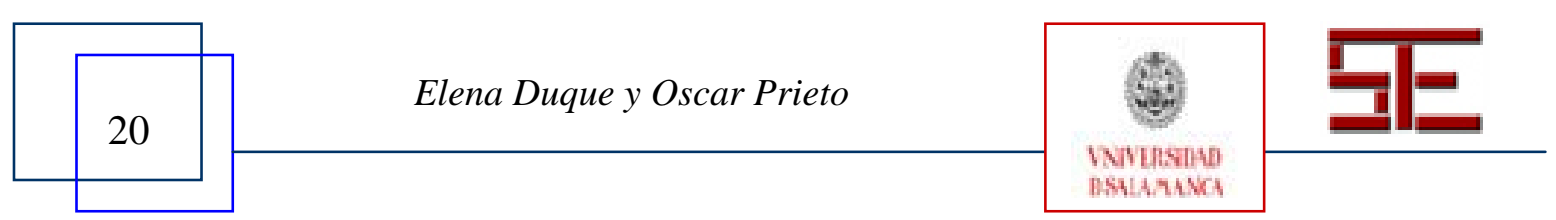




\begin{tabular}{c|c} 
Revista Electrónica Teoría de la Educación. \\
Educación y Cultura en la Sociedad de la Información.
\end{tabular}

según el autor una de las formas de acabar con él está en formar a las y los estudiantes para que analicen de forma crítica los contenidos escolares.

\section{2.- Creación dialógica de sentido}

El Aprendizaje Dialógico se enmarca en una sociedad actual que está viviendo un giro dialógico (Flecha, Gómez y Puigvert, 2001) en el que el diálogo va sustituyendo los criterios de autoridad, y actúa ante las crisis de sentido (educativas y no educativas) reencantando las relaciones entre las personas y permitiendo que cada una tome las decisiones pertinentes para reorientar su vida. "Las sociedades actuales son cada vez más dialógicas. [...] las sociedades de la información son el contexto simbólico donde el diálogo está penetrando en las relaciones sociales, desde la política internacional hasta la convivencia dentro de un domicilio” (Flecha, Gómez y Puigvert, 2001, 148).

Desde el Aprendizaje Dialógico, el sentido de la educación se crea, al igual que el aprendizaje, a través de las interacciones y mediante el diálogo igualitario. De esta manera, la diversidad de opciones y el riesgo de las elecciones en la sociedad actual lejos de generar crisis de sentido permite que todas las niñas y niños puedan crear sentido tomando sus propias decisiones y dirigiendo su propia biografía. "El Aprendizaje Dialógico rompe con cualquier determinismo social y busca ofrecer un abanico mayor de posibilidades para que los y las estudiantes contemplen otras opciones y decidan libremente qué sentido o qué orientación quieren darle a sus vidas” (Aubert, Duque, Fisas y Valls, 2004, 131).

El diálogo igualitario entre toda la comunidad educativa y la promoción de más y más diversas interacciones dialógicas posibilita la creación de sentido. Al conectarse la realidad vivida por las y los estudiantes con los conocimientos escolares, la educación adquirida cobra sentido, los conocimientos escolares ya no están estancados y descontextualizados sino que conectan y sirven para entender el mundo de la vida. Las experiencias del mundo de la vida también dan sentido y ayudan a comprender mejor los conocimientos escolares. El hecho de que en la educación escolar participe toda la comunidad educativa facilita estas transferencias entre centro educativo y vida cotidiana.

Por otra parte, la capacidad de reflexión de los y las estudiantes es otro elemento clave en el Aprendizaje Dialógico tanto para la dimensión instrumental como para la creación de sentido. "En este sentido, es esencial que en los centros tengamos en cuenta la capacidad del niño o niña de reflexionar sobre lo que el profesorado explica, re-elaborarlo y emitir su propia opinión e interpretación, relacionándolo con lo que ha aprendido no sólo en el centro educativo sino también en otros contextos” (Aubert, Flecha, García, Flecha y Racionero, 2008, 221).

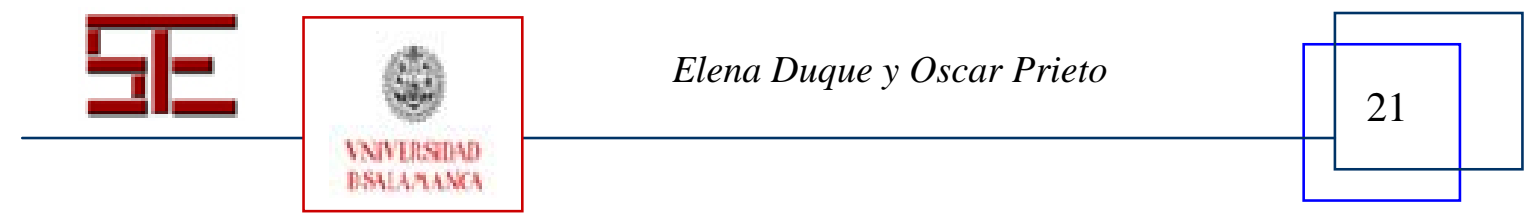


Además de la conexión entre lo que ocurre fuera y dentro del aula, para la creación de sentido, se hace necesaria la coherencia entre lo que la escuela "promueve" y lo que la escuela "hace". La incoherencia entre los contenidos transmitidos y la realidad vivida en los centros escolares es una de las principales causas de la pérdida de sentido. Muchas escuelas incluyen en sus contenidos curriculares y en sus actividades la defensa de la diversidad cultural, la igualdad de derechos. Algunas de estas escuelas, sin embargo, colocan a las niñas y niños inmigrantes en los grupos de más bajo nivel; presuponen que sus familiares no están interesados en la educación de sus hijas e hijos, no pueden ni quieren participar en la escuela. Ponen barreras burocráticas y lingüísticas a su participación y no escuchan sus sugerencias ni sus quejas. Otras escuelas se definen como coeducativas en sus proyectos educativos. Algunas de ellas centran sus discursos en "hacer ver" al alumnado cómo sus madres que han decidido ser amas de casa están sometidas, y cómo sus padres que no realizan de forma equitativa las tareas del hogar son machistas (casualmente estas familias suelen ser además las más desfavorecidas), mientras que los modelos femeninos emancipados a seguir son las propias profesoras del centro. Sin embargo, algunas de estas mismas escuelas cuando las niñas "se quejan" de que los niños les levantan la falda no las toman en serio, no se posicionan firmemente y argumentan que "son cosas de niños”. Todas estas incoherencias generan una pérdida de sentido y vacían de significado los términos de igualdad y de solidaridad. Para dar sentido a la educación es necesario que estos valores sean vividos en la cotidianeidad de la escuela. "Si la escuela es un lugar en el que se aprende, si se vive sin discriminaciones ni segregaciones, si hay una confianza en las personas y en su capacidad para aprender un currículo de máximos, la propia educación también cobra sentido” (Aubert, Duque, Fisas y Valls, 2004, 132).

\section{7.- SOLIDARIDAD}

Tradicionalmente, un aprendizaje instrumental de calidad se ha presentado como opuesto a un aprendizaje a través de la solidaridad y la cooperación. La competitividad y el trabajo individual se han utilizado para la mejora del aprendizaje en algunos centros educativos. En estos mismos centros, y en otros, según han aparecido conflictos y/o problemas de indisciplina se ha empezado a trabajar la mejora de la convivencia y la solidaridad desvinculada de la calidad del aprendizaje. Por un lado, se pretende enseñar a ser solidarios y solidarias mientras por otro lado se potencia el individualismo para aprender más y obtener mejores resultados. Sin embargo, autores como Slavin (1995) plantean cómo trabajando de forma cooperativa mejoran tanto las relaciones entre el alumnado (solidaridad) como aumentan los aprendizajes. Desde el planteamiento del Aprendizaje Dialógico, solidaridad y aprendizaje van unidos. En el caso de los grupos interactivos, el aumento del aprendizaje se realiza mientras se trabaja solidariamente. (Aubert y García, 2001).

El aprendizaje de la solidaridad, por otro, lado no puede aprenderse de forma descontextualizada ni de forma incoherente. Como se comentaba en el principio anterior, realizar

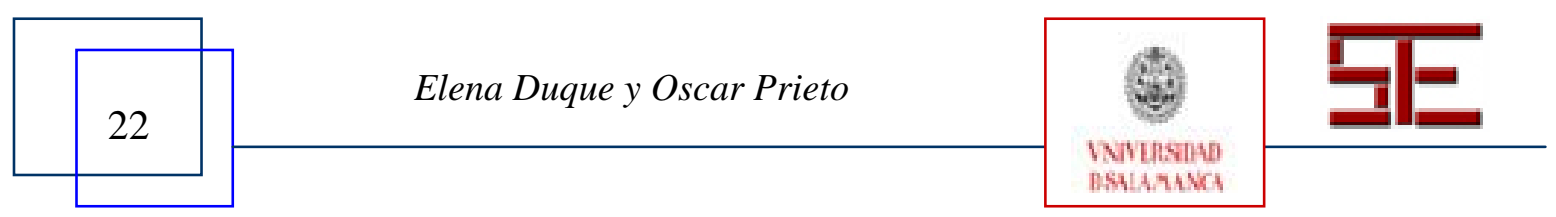




\begin{tabular}{c|c} 
Revista Electrónica Teoría de la Educación. \\
Educación y Cultura en la Sociedad de la Información.
\end{tabular}

actividades sobre solidaridad cuando en el centro educativo se trata de forma desigual al alumnado crea una pérdida de sentido, y, evidentemente, no genera un aprendizaje de la solidaridad. "La solidaridad como valor educativo es algo que no se consigue más que a través de la práctica solidaria, como un valor que se pone en práctica en las interacciones que desarrollamos en el aula" (Aubert, Duque, Fisas y Valls, 2004,134). Las y los profesionales de la educación tienen un papel esencial en fomentar esta solidaridad, mediante sus acciones y actitudes. Estos profesionales se comportan de forma solidaria cuando, como se comenta en el principio de transformación, proceden como intelectual transformativo (1988) es decir, cuando actúan para cambiar las injusticias y desigualdades, no cuando las aceptan ni cuando se limitan a criticar las desigualdades existentes. Ferrer i Guàrdia (1908) ya planteaba la necesidad de actuar en este sentido para la transformación de las desigualdades "Enemigo de la desigualdad social, no me limité a lamentarla en sus efectos, sino que quise combatirla en sus causas, seguro de que de ese modo se ha de llegar positivamente a la justicia, es decir, a aquella ansiada igualdad que inspira todo afán revolucionario." Un planteamiento educativo desde el Aprendizaje Dialógico, un proyecto educativo con pretensiones igualitarias requiere que sea así mismo solidario. "Una educación solidaria tiene que ofrecer los máximos aprendizajes y de la máxima calidad a todos y cada uno de los y las estudiantes independientemente de cualesquiera que sean sus diferencias”. (Aubert, Flecha, García, Flecha y Racionero, 2008, 225).

\section{8.- IGUALDAD DE DIFERENCIAS}

Los planteamientos por una educación igual para todos los colectivos y los planteamientos educativos que pretenden respetar y tener en cuenta las diferencias sociales e individuales del alumnado suelen presentarse como opuestos; aunque tampoco es extraño que ambos en ocasiones generen el mismo resultado: poca calidad educativa para los grupos más desfavorecidos y promoción de la exclusión social.

Ante una educación tradicional e históricamente elitista, el objetivo de una educación igual para toda la población ha sido un avance educativo clave hacia una educación democrática e inclusiva. Pasar de educar a "privilegiados" a educar a "toda la población" ha sido un paso enorme y de gran valor educativo y social.

Sin embargo, este objetivo de igualdad educativa se ha convertido en múltiples ocasiones en una pretensión de homogeneización basada en un etnocentrismo educativo. "El etnocentrismo afirma estar en contra de la existencia de escuelas basadas en otras culturas e incluso de la introducción de elementos de estas en el currículo. Se plantea un currículo único basado en la cultura hegemónica, junto a la distribución y asimilación del alumnado inmigrante y de minorías étnicas, ya que el fracaso escolar se atribuye a su concentración en las aulas” (Elboj, Puigdellívol, Soler, Valls, 2002, 122). El objetivo de una educación de calidad se ve amenazado, desde esta perspectiva, por el acceso a la

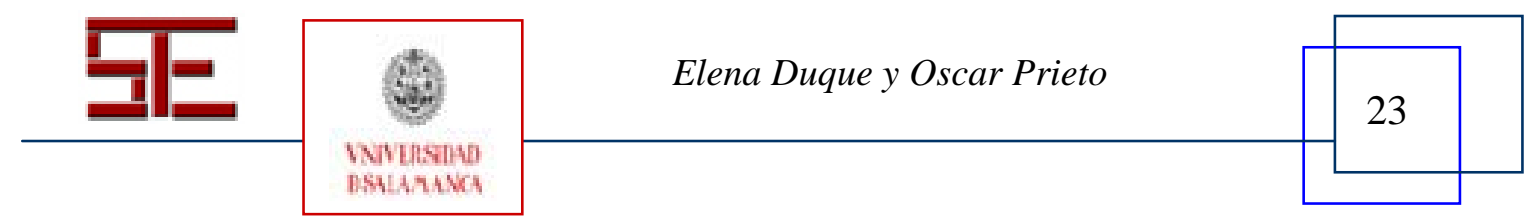


educación de minorías étnicas y de clases socialmente más desfavorecidas. La organización escolar y los contenidos impartidos se realizan de forma "igual" para todo el alumnado, mismos contenidos, misma forma de impartirlos, mismos procesos, todos ellos acordes con un modelo hegemónico, condenando al fracaso a aquellos colectivos que no se corresponden con este modelo.

El respeto por las diferencias culturales y la perspectiva educativa de atención a la diversidad han derivado con frecuencia en el fomento de mayores desigualdades. Se pierde de vista el objetivo igualitario (primordial en la pedagogía crítica) y se defiende la diferencia como un valor nuevo (cuando siempre ha existido). Consecuentemente, se pasa de buscar un aprendizaje homogéneo a adaptar el aprendizaje a la diversidad existente, sin tener en cuenta las desigualdades que sufren algunos colectivos. De esta forma, se enseñan contenidos de menos calidad a los grupos más desfavorecidos. La diversidad se trata de forma que se reproducen las desigualdades argumentando que es una educación adaptada a las diferencias.

Sin embargo, son diversos los autores que no entienden la diversidad ni como un problema para la educación de calidad, ni como una realidad que requiere de adaptaciones desiguales. Para Macedo (2005), Cummins (2002) y Freire (1997), entre otros, la diversidad es entendida como riqueza para el aprendizaje escolar de todos los y las estudiantes.

La igualdad de diferencias (Flecha, 1997) entiende que la igualdad como principio incluye el derecho de cada persona a ser diferente. La igualdad es opuesta a la desigualdad, pero no a la diferencia ni a la diversidad. Por tanto, el objetivo igualitario de la educación incluye la diversidad como riqueza, y respeta las diferencias sin excluirlas ni rebajar los objetivos educativos a ningún colectivo. Una educación de calidad es un objetivo para todas y todos los estudiantes independientemente de su origen y contexto social y cultural. El alcance de este objetivo no requiere que nadie renuncie ni pierda su identidad individual ni colectiva. "Más allá de una igualdad homogeneizadora y de una defensa de la diversidad sin contemplar la equidad entre personas, la igualdad de diferencias se orienta hacia una igualdad real, donde todas las personas tienen el mismo derecho a ser y vivir de forma diferente y, al mismo tiempo, ser tratadas con el mismo respeto y dignidad”. (Aubert, Flecha, García, Flecha y Racionero, 2008, 234).

\section{9.- CONCLUSIONES}

La teoría del Aprendizaje Dialógico presentada en este artículo es crítica no sólo con los procesos de modernización que ha experimentado la escuela en particular y el mundo de la educación en general hasta nuestros días, sino también con algunas interpretaciones analíticas, como el constructivismo radical o el estructuralismo marxista, que por un lado, han legitimado -intencionadamente o no - las desigualdades sociales y, por el

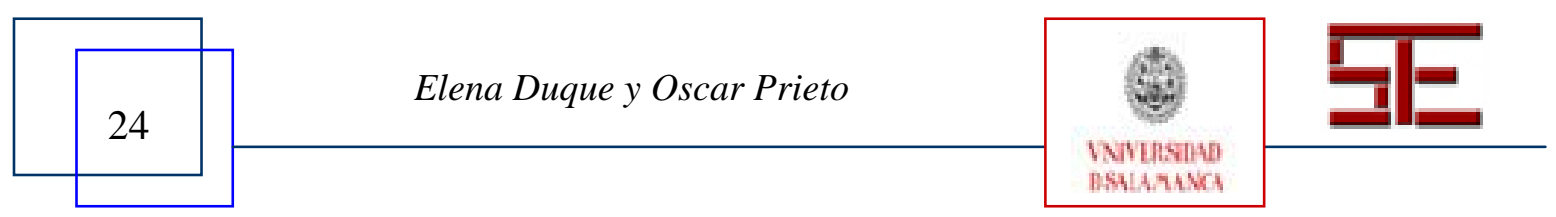




\begin{tabular}{c|c} 
Revista Electrónica Teoría de la Educación. \\
Educación y Cultura en la Sociedad de la Información.
\end{tabular}

otro, han difundido un mensaje pesimista de que ni la escuela, ni la familia ni la comunidad podían hacer alguna aportación al cambio educativo y social. Si bien es cierto que, tradicionalmente, el sistema educativo ha tendido a dejar a un lado al alumnado de clase baja o de algunas minorías étnicas como la población indígena, gitana o árabemusulmana; también es necesario identificar qué prácticas de éxito existen y cómo éstas superan las desigualdades educativas y sociales. Dicha tarea no es fácil debido a la complejidad de las relaciones existentes. Ahora bien, teniendo también en cuenta el análisis no sólo de la escuela hegemónica sino de proyectos educativos que están dando buenos resultados se puede llegar a una mayor identificación de cuáles son los obstáculos a superar y cómo una educación crítica también puede promover el éxito académico de todos y todas. Ésta es una labor que la pedagogía crítica ha dejado un poco de lado al centrarse excesivamente en algunos casos, y exclusivamente en otros, en la identificación de los mecanismos de reproducción del poder y de la violencia simbólica. El Aprendizaje Dialógico aporta a la pedagogía crítica, a través del análisis y debate entre teorías hegemónicas y críticas, investigaciones científicas y prácticas educativas de éxito, los planteamientos educativos que conllevan a la transformación social y a la superación de las desigualdades.

La teoría presentada dialoga con la realidad educativa dentro y fuera de las aulas en contextos educativos diferentes. No es que lo presentado forme parte sólo de una utopía -o ideología como comentan los científicos que se autodenominan como "neutrales" sino más bien de lo que Erik Olin Wright ha conceptualizado como utopía real, de cómo los sueños de los sujetos pueden transformar la realidad en la que viven y sus instituciones (Wright, 2009). Estos siete principios reflejan las principales características que ilustran cómo algunas comunidades han reformulado los centros educativos y su relación con el entorno.

Los siete principios del Aprendizaje Dialógico aportan a la pedagogía crítica, como hemos mencionado anteriormente, los elementos educativos que promueven la superación de desigualdades sociales. Las interacciones dialógicas que promueven que diálogo y aprendizaje instrumental se alimenten mutuamente, el compromiso de los profesionales de la educación con la transformación social, la solidaridad llevada a la práctica en la búsqueda del éxito escolar para todo el alumnado, la creación de sentido a través de la educación, el reencanto con la educación y el centro educativo a través del diálogo, la inclusión de los grupos más desfavorecidos generando éxito educativo para toda la población, la igualdad educativa que favorece la diversidad cultural, de género..., y la valoración de la inteligencia cultural y comunicativa de todas las personas son algunos elementos de los siete principios que contribuyen al avance de las teorías de la pedagogía crítica.

Todo modelo teórico y toda práctica educativa comportan algunas limitaciones cuando se intentan extrapolar a otros contextos. De forma crítica, es necesario reflexionar sobre los principios presentados e identificar cuáles de ellos se aplican (o no) y cómo se llevan

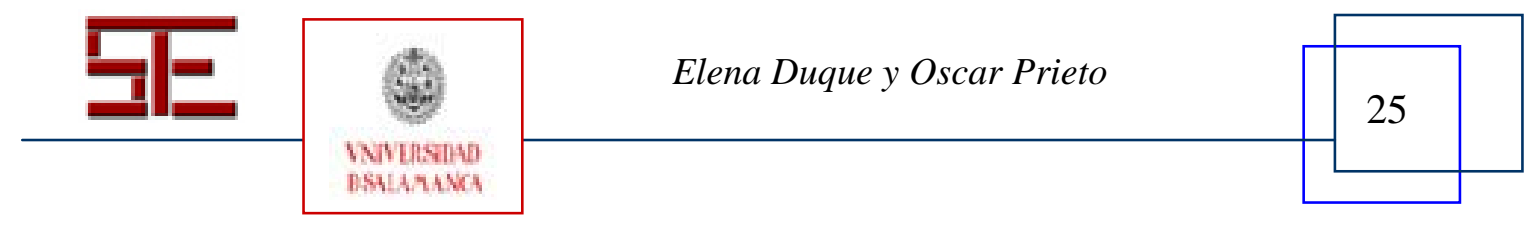


TESI, 10(3), 2009, 7-30

a cabo. Se vuelve necesario que la pedagogía crítica ahonde más profundamente en teorías y prácticas que contribuyan no sólo con la transmisión de una educación crítica sino también en una educación que promueva el éxito académico de aquellos y aquellas que suelen quedarse al margen de la sociedad. El trabajo teórico y práctico en esta dirección conlleva implícitamente la ampliación y/o reconceptualización de algunos presupuestos que se han presentado en este artículo promoviendo, enriqueciendo y fortaleciendo el debate científico. En este sentido, el Aprendizaje Dialógico aporta teorías, prácticas y evidencias empíricas de las estrategias educativas que contribuyen a la transformación social y a la superación de las desigualdades sociales a través de la educación.

\section{0.- BIBLIOGRAFÍA}

APPLE, M. W. y BEANE, J. A. (1995): Escuelas democráticas. Madrid, Morata.

AUBERT, A.; DUQUE, E.; FISAS, M. y VALLS, R. (2004): Dialogar y transformar. Pedagogía crítica del siglo XXI. Barcelona, Graó.

AUBERT, A.; FLECHA, A.; GARCÍA, C.; FLECHA, R. y RACIONERO, S. (2008): Aprendizaje Dialógico en la Sociedad de la Información. Barcelona, Hipatia.

AUBERT, A. y GARCÍA, C. (2001): Interactividad en el aula, Cuadernos de Pedagogía, 301, 20-24.

AUSUBEL, D. P. (1962): A subsumption theory of meaningful verbal learning and retention, Journal of General Psychology, 66, 213-224.

-- (1963): The psychology of meaningful verbal learning. New York, Grune and Statton.

AUSUBEL, D. P.; NOVAK, J. D. y HANESIAN, H. (1978): Educational psychology: A cognitive view. New York, Holt, Rinehart, and Winston.

BAUDELOT, Ch. y ESTABLET, R. (1972): L'École capitaliste en France. Paris, François Maspero.

BERNSTEIN, B. (1971): Class, Codes and Control. New York, Routledge.

BOURDIEU, P. y PASSERON, J. C. (1970): La reproduction. Élements pour une théorie au système d'enseignement. Paris, Éditions de Minuit.

BOWLES, S. y GINTIS, H. (1976): Schooling in Capitalist America: Educational Reform and the Contradictions of Economic Life. New York, Basic Books.

CARNOY, M.; GOVE, A. K. y MARSHALL, J. H. (2007): Cuba's Academia Advantage. Why students in Cuba do better in School. Stanford, Stanford University Press.

CHOMSKY, N. (1988): Language, mind and politics. New York, Black Rose Books.

COLE, M.; y SCRIBNER, S. (1977): Cultura y pensamiento. Relación de los procesos cognoscitivos con la cultura. México, Limusa.

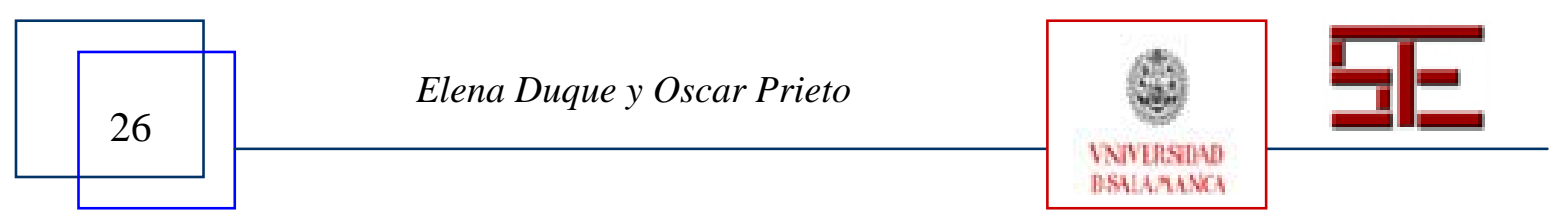


CREA (2006-2011): INCLUD-ED. Strategies for inclusion and social cohesion from education in Europe, FP6 028603-2. Sixth Framework Programme. Priority 7 Citizens and governance in a knowledge-based society. European Commission.

CUMMINS, J. (2002): Lenguaje, poder y pedagogía. Niños y niñas bilingües entre dos fuegos. Madrid, Ministerio de Educación, Cultura y Deporte - Ediciones Morata.

DEWEY, J. (1916): Democracy and Education. New York, The Free Press.

ENGESTRÖM, Y. (1996): "Non scolae sed vitae discimus: Toward overcoming the encapsulation of school learning”, en DANIELS, H. (ed.): An introduction to Vygotsky. London and New York: Routledge, 151-170.

FERRER I GUÀRDIA, F. (1908) La Escuela Moderna. www.antorcha.net/biblioteca_virtual/pedagogia/escuelamoderna.

FLECHA, R. (1997): Compartiendo palabras. Barcelona, Paidós.

FLECHA, R. GÓMEZ, J. y PUIGVERT, L. (2001): Teoría sociológica contemporánea. Barcelona, Paidós.

FREIRE, P. (1970): Pedagogía del oprimido. Madrid, Siglo XXI.

-- (1997): A la sombra de este árbol. Barcelona, El Roure Ciencia.

-- (1999): Pedagogía de la esperanza. Madrid, Siglo XXI.

GARDNER, H. (1983): Frames of Mind. The Theory of Multiple Intelligences. New York, Basic Books.

GIROUX, H. A. (1988): Teachers as Intellectuals: Toward a Critical Pedagogy of Learning. Wesport, Bergin \& Garvey Paperback.

GRAMSCI, A. et al. (1935): The Antonio Gramsci Reader: Selected Writings 19161935. New York, NYU Press.

KINCHELOE, J. L. (2008): Knowledge and Critical Pedagogy: An Introduction. New York, Springer.

KINCHELOE, J.L.; STEINBERG, S. y VILLAVERDE, L. (1999): Rethinking Intelligence: Confronting Psychological Assumptions about Teaching and Learning. New York, Routledge.

HABERMAS, J. (1981): Teoría de la acción comunicativa. Volumen I: Racionalidad de la acción y racionalización social y Volumen II: Crítica de la razón funcionalista. Madrid, Taurus.

HANUSHEK, E. (2002): Teacher Quality, en IZUMI, L.T. y EVERS, W. M. (eds.) Teacher Quality. Stanford, Hoover Press, 1-13.

HERRNSTEIN, R. y MURRAY, Ch. (1994): Bell curve. Intelligence and Class Structure in American Life. New York, Free press.

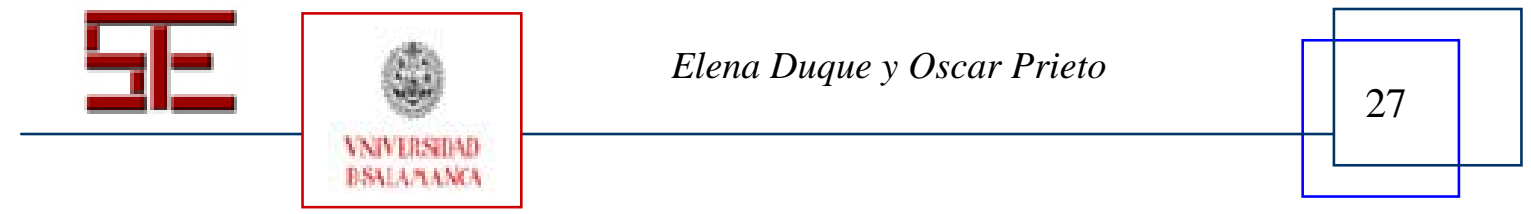


JENCKS, Ch. (1972): Inequality: A Reassesment of the Effect of Family and Schooling in America New York, Basic Books.

LADSON-BILLINGS, G. (1994): The dreamkeepers: Successful teachers of African American children. San Francisco, Jossey-Bass.

-- (1995): Toward a theory of culturally relevant pedagogy, American Educational Research Journal, 32 (3), 465-491.

LAKATOS, I. y MUSGRAVE, A. (1970): Criticism and the Growth of Knowledge. Cambridge, Cambridge University Press.

MACEDO, D.; DENDRINOS, B. y GOUNARI, P. (2005): Lengua, ideología y poder. Barcelona, Graó.

MEAD, G. H. (1934): Mind, Self and Society. From the Standpoint of Social Behaviorist. Chicago, University of Chicago Press.

MERTON, R. K. (1977): Sociología de la ciencia. Madrid, Alianza.

ROGOFF, B. (1993): Aprendices del pensamiento. El desarrollo cognitivo en el contexto social. Barcelona, Paidós.

SEARLE, J. y SOLER, M. (2004): Lenguaje y ciencias sociales. Diálogo entre John Searle y CREA. Barcelona, El Roure Ciencia.

SEN, A. (1997): Human Capital and Human Capability, World Development, 25 (12), 1959-1961.

SLAVIN, R. E. (1995): “Cooperative learning and intergroup relations”, en BANKS, J. y BANKS, C. M. (eds.): Handbook of research on multicultural education. New York, Macmillan, 628-634.

SOLÀ, P. (2008): L’educació en el context de la fundació de l'Institut d'Estudis Catalans, en AAVV: Pedagogia, política i transformació social (1900-1917). Barcelona: Institut d'Estudis Catalans, 169-193.

SORDÉ, T. (2006): Les reivindicacions educatives de la dona gitana. Barcelona, Galerada.

STERNBERG, R. J. y WAGNER, R. K. (1986): Practical Intelligence. Cambridge, Cambridge University Press.

VYGOTSKY, L. S. (1920a): Thought and Language. Cambridge, MIT Press.

-- (1920b): Mind and Society: Development of Higher Psychological Processes. Cambridge, Harvard University Press.

WEBER, M. (1919): El político y el científico. Madrid, Alianza editorial.

--(1922): Economy and Society: An Outline of Interpretative Sociology. Los Angeles, University of California Press.

WELLS, G. (2001): Indagación dialógica. Hacia una teoría y una práctica socioculturales de la educación. Barcelona, Paidós.

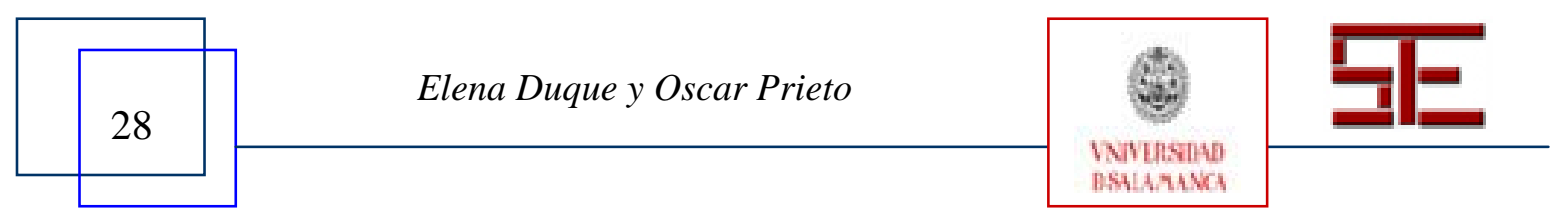




\begin{tabular}{c|c} 
Revista Electrónica Teoría de la Educación. \\
Educación y Cultura en la Sociedad de la Información.
\end{tabular}

WRIGHT, E. O. (2009): Envisioning Real Utopias. New York, Verso.

\section{Notas}

${ }^{1}$ La neutralidad valorativa en ciencia o la ciencia del expertismo se entiende como la posición neutral que toma el científico o científica en su trabajo académico o investigador dejando de lado sus opiniones y su moral centrándose exclusivamente en una visión analítica o contemplativa. Esta tarea sería una misión imposible ya que todo investigador "neutral" o no tiende a introducir sus juicios de valor en el proceso investigador. Según Max Weber, los juicios de valor y la opinión política no tendrán cabida en las aulas ni por parte del alumnado ni del profesorado ya que el contenido de las clases o investigaciones no serían fruto del análisis científico sino de la toma de una posición política concreta. Ahora bien, cabe destacar que Weber vivió en un contexto social concreto a principios del siglo XX y que tenía una concepción tradicional del aprendizaje destacando, por ejemplo, que "en el aula es el profesor el que habla en tanto que los oyentes han de callar; para hacer su carrera, los estudiantes están obligados a asistir a las clases del profesor, y en ellas no se le permite a nadie hacerle críticas. Me parece de una falta de responsabilidad que el profesor aproveche estas circunstancias para marcar a los estudiantes con sus propias opiniones políticas” (Weber, [1919] 2001, 214-215). Desde nuestro punto de vista si bien es importante llevar a cabo un análisis científico de la realidad también se vuelve indispensable preguntarse por los juicios de valor que toda práctica de la palabra conlleva (Freire, 1999).

2 Por pretensiones de validez se entiende aquella orientación de la acción que conlleva establecer un diálogo con otros sujetos sin intentar convencer a nadie de que la opción que se presenta es la que se ha de aceptar. Ésta se presenta por sí sola basada en los argumentos que los actores proponen bajo las premisas de verdad, rectitud y veracidad, y se lleva a debate y a consenso (Habermas. [1981] 1999).

${ }^{3}$ Los grupos interactivos son "la organización del aula en pequeños grupos heterogéneos de alumnado (a nivel de conocimiento en cada área, género, cultura, lengua, motivaciones, etc.), unos cuatro o cinco estudiantes por grupo, en los que se hacen actividades de corta duración, entre quince y veinte minutos. En cada grupo, una persona adulta voluntaria se encarga de fomentar las interacciones entre el alumnado de forma que todos y todas se ayuden y resuelvan con éxito las actividades que se plantean. Mientras cada grupo realiza las actividades, el profesorado gestiona el aula. De esta forma, en una misma aula podemos encontrar cinco personas adultas, diferentes tipos de profesionales y voluntariado. Con esta organización interactiva, los aprendizajes son dobles en una misma dinámica: más aprendizaje instrumental y más solidaridad”. (Aubert, A.; Flecha, A.;García, C.;Flecha, R.;Racionero, S., 2009, 107-108).

${ }^{4}$ Para información, ver http://www.comunidadesdeaprendizaje.net.

${ }^{5}$ Aunque las relaciones dialógicas que se establecen en la sociedad no sean puras existe una serie de acuerdos en la comunidad educativa para que se establezcan interacciones que tienden hacia el diálogo y no hacía la tecnocracia, la inhibición o la imposición.

${ }^{6}$ A lo largo de este artículo se han utilizado indistintamente nombres masculinos y femeninos para hacer más ligera la lectura y no caer en una lectura exclusivamente masculina del mundo.

${ }^{7}$ INCLUD-ED es actualmente el proyecto integrado europeo sobre educación escolar de mayor nivel científico y más recursos destinados por la Comisión Europea. CREA (2006-2011): INCLUD-ED. Strategies for inclusion and social cohesion from education in Europe, FP6 028603-2. Sixth Framework Programme. Priority 7 Citizens and governance in a knowledge-based society. European Commission.

${ }^{8}$ Para más información, ver http://www.hcz.org/.

${ }^{9}$ Brudila Callí: Las mujeres gitanas contra la exclusión. Superación del absentismo y fracaso escolar de las niñas y adolescentes gitanas. Plan Nacional I+D+I. Instituto de la Mujer, Comisión Interministerial de Ciencia y Tecnología, Ministerio de Trabajo y Asuntos Sociales (2000-2003).

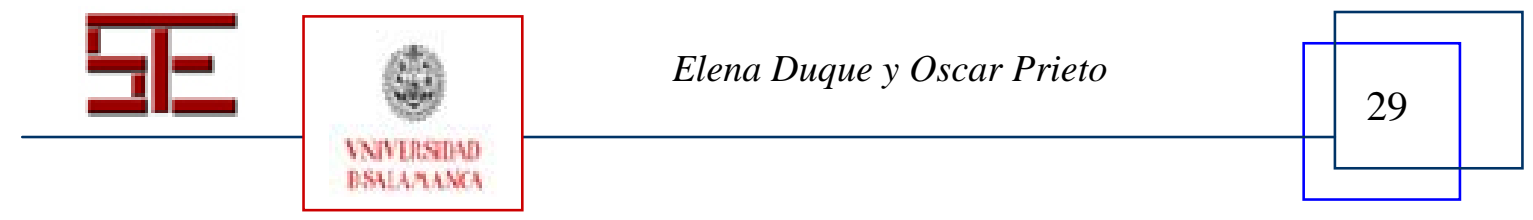


Revista Electrónica Teoría de la Educación.

Educación y Cultura en la Sociedad de la Información.

TESI, 10(3), 2009, 7-30

Para citar el presente artículo puede utilizar la siguiente referencia:

DUQUE, E. y PRIETO, O.: (2009). El aprendizaje dialógico y sus aportaciones a la teoría de la educación, en FLECHA GARCÍA, R. y STEINBERG, S. (Coords.) Pedagogía Crítica del S. XXI [monográfico en línea]. Revista Electrónica Teoría de la Educación: Educación y Cultura en la Sociedad de la Información. Vol. 10, nº 3. Universidad de Salamanca, pp. 7-30. [Fecha de consulta: dd/mm/aaaa]. http://campus.usal.es/ revistas_trabajo/index.php/revistatesi/article/view/3930/3999 ISSN: $1138-9737$ 